\title{
Susceptibility of Four Trichogrammatid Parasitoids to some Bio-rational Insecticides Used to Control Tomato Leaf Miner Tuta absoluta (Lepidoptera, Gelechiidae)
}

\author{
Osman M. A. M.*; N. S. Mandour; M. A. Abd El-Hady and A. A. Sarhan \\ Plant Protection Department, Faculty of Agriculture, Suez Canal University 41522, Ismailia, Egypt
}

Received: $20 / 12 / 2014$

\begin{abstract}
Laboratory bioassays were performed to evaluate the susceptibility of four species of trichogrammatid egg parasitoids to the toxicity of five bio-rational insecticides used widely to control tomato leaf miner, (TLM) Tuta absoluta (Lepidoptera: Gelechiidae). The selected parasitoids were Trichogramma evanescens (West.), T. cacoeciae (Brun), T. pretiosum (Riley), and Trichogrammatoidea bactrae (Nagaraja). Insecticides tested were coragen 20\% SC, dipel $2 \times 6.4 \%$, match $50 \%$ EC, proclaim 5\% EC and spintor $24 \%$ SC. Susceptibility of parasitoids to field rate of the tested insecticides were evaluated using three bioassay tests: 1) exposing parasitoid females to TLM eggs treated preexposure, 2) exposing parasitoid females to TLM eggs treated post-exposure, and 3) exposing parasitoid females to dry insecticide residue on filter paper. Results revealed that the tested insecticides showed various degree of adverse impact on all tested parasitoid species, including reduction in rates of parasitism and adult emergence when exposing parasitoids adults to host eggs treated pre or post exposure. Spintor and proclaim were the most toxic to tested parasitoids, while dipel $2 \times$ and match were slightly toxic. $T$. bactrae was the most tolerant parasitoid species, while $T$. pretiosum was the most susceptible one. Data of exposing parasitoid adults to insecticide residues indicated that proclaim had the highest toxicity against $T$. pretiosum at $92.5 \%$ adults' mortality, followed by spintor against the same species at $85 \%$. T. evanescens was more susceptible to coragen and spintor at 70 and $62.5 \%$ mortality, respectively. Meanwhile, match caused moderate toxicity, as the mortality ranged from $17.50 \%$ in $T$. evanescens to $37.50 \%$ in $T$. pretiosum.
\end{abstract}

Keywords: Bio-rational insecticides, Parasitism, Parasitoid emergence, Toxicicty, Trichogrammatidae, Tuta absoluta

\section{INTRODUCTION}

The tomato leafminer (TLM), Tuta absoluta (Meyrick) (Lepidoptera: Gelechiidae), is one of the most destructive invasive insect pests attacking tomato crop in Mediterranean basin countries (Desneux et al., 2010; Desneux et al., 2011; Tropea Garzia et al., 2012). In Egypt, it was first recorded infesting tomato crop in Western desert in the late of 2009 (Temerak, 2011). Since its detection in Egypt, it spread rapidly to become a key insect pest on tomato crop in both open field and protected greenhouse. This pest is capable of causing major economic losses in tomatoes of up to 80100\% (EPPO 2005; Picanco et al., 2007; Desneux et al., 2010). Thus, developing and implementing effective control tactics of this pest are rather essential in order to prevent possible potential damage caused by this pest.

Integrated pest management (IPM) strategies emphasize the use of multiple tactics based on economically and ecologically sound manner. Beneficial insects play a vital role in the agro-ecosystem and are a realistic management tool in integrated pest management. Egg parasitoid species of the family Trichogrammatidae are considered efficient biological control agents and are commercially used for the suppression and control of various lepidopterous pests on many crops (Caltagirone and Huffaker, 1980), including TLM on tomato crop (Pratissoli and Parra, 2001).

In spite the vital role of the biological control agents for controlling agricultural pests, the use of chemical insecticides is still inevitable. Unfortunately, the commonly used insecticides are toxic to many nontarget organisms particularly hymenopterans parasitoids, and greatly reduce their potential as biocontrol agents (Desneux et al., 2007; Stark and Banks, 2003). Selective pesticides that can be used to control pests without adversely affecting natural enemies are urgently needed for integrated control programs (Hafez et al., 1999).

Recently, great attention has been given to maintain environment and keep natural balance, which might be achieved in the field for pest control by using biorational insecticides and natural enemies. However, it is very important to study the adverse effects of these biorational insecticides on the natural enemies to exclude the ones that have detrimental effect on such natural enemies. A range of harmful effects of insecticides on Trichogramma spp. have been reported by several researches (Hewa-Kapuge et al., 2003; Desneux et al., 2007; Vianna et al., 2009).

Therefore, the current research aimed to verify the adverse effect of five bio-rational insecticides, which are widely used to control TLM in tomato fields, on the parasitism efficiency, adult emergence, as well as their direct toxicity on the adult stage of four trichogrammatid egg parasitoids under laboratory conditions.

\section{MATERIALS AND METHODS}

Source and maintenance of parasitoid species:

Four trichogrammatid egg parasitoid species (Hymenoptera: Trichogramatidae) were investigated; i.e., Trichogramma evanescens (West.), T. cacoeciae (Brun), T. pretiosum (Riley), and Trichogrammatoidea bactrae (Nagaraja). The source of T. evanescens (West.) was obtained from the mother colony kept in the laboratory of Biological Control Center (BCC), Suez Canal University (SCU). As for T. cacoeciae (Brun) and 
Tr. bactrae (Nagaraja), wasps were kindly provided by Prof. Essam Agamy (Faculty of Agriculture, Cairo University) and Prof. Ahmad El-Heneidy (Agricultural Research Center), respectively. In case of $T$. pretiosum (Riley), the wasp was imported from Berkely, California University, USA. All parasitoids were maintained on the Angoumois grain moth, Sitotroga cerealella (Lepidoptera: Gelichiidae) eggs for several generations under laboratory conditions.

Maintenance of target pest and preparing egg cards:

Tomato leaf miner (TLM) was reared on tomato seedlings placed in a rearing cage $(40 \times 60 \times 80 \mathrm{~cm})$ under laboratory conditions of $25 \pm 2{ }^{\circ} \mathrm{C} ; 60 \pm 10 \% \mathrm{RH}$ and photoperiod of 14: 10 (L: D) h. This pest was reared and maintained for at least 3 generations before being used in this experiment. Newly laid TLM eggs (less than $24 \mathrm{~h}$ old) were glued onto small cartoon cards, each containing 10 eggs. These egg cards were prepared one hour prior to assay and placed into glass tubes.

\section{Tested bio-rational insecticides:}

Commercial formulations of the bio-rational insecticides tested in this study were coragen $20 \%$ SC (chlorantraniliprole), dipel $2 \times \quad 6.4 \% \quad$ (Bacillus thuringensis var. kurstaki $32000 \mathrm{IU} / \mathrm{mg}$ ), match 50\% EC (lufenuron), proclaim 5\% SG (emamectin benzoate), and spintor 24\% SC (spinosyns A and D, Saccharopolyspora spinosa). Solutions of all tested compounds were prepared in distilled water at the recommended field rate (FR), (coragen $60 \mathrm{mg} / \mathrm{l}$ a.i., dipel $2 \times 128 \mathrm{mg} / \mathrm{l}$ a.i., match $200 \mathrm{mg} / \mathrm{l}$ a.i., proclaim 30 $\mathrm{mg} / \mathrm{l}$ a.i. and spintor $60 \mathrm{mg} / \mathrm{l}$ a.i.). The tested concentration of each compound was freshly prepared one hour prior to assay.

\section{Bioassay toxicity assessment tests:}

The susceptibility of the four tested oophagous parasitoids to the tested bio-rational insecticides was conducted in the laboratory using their field rates. Fresh solutions of the tested bio-rational insecticides were prepared one hour prior to use. To ascertain the toxicity of spraying bio-rational insecticides on the four tested trichogrammatid species, three groups of assessment tests were conducted. These groups included a) exposing parasitoid adult females to treated TLM eggs, b) exposing parasitoid adult females to TLM eggs prior to treatment and c) exposing parasitoid adult females to treated filter paper in Petri dishes.

\section{a. Exposing parasitoid females to treated host eggs:}

Small egg cards, each containing 10 unparasitized eggs of TLM, were dipped for 5 seconds in freshly prepared solution of the recommended rates of the tested bio-rational insecticides. Each treatment of biorational insecticide was replicated four times (four cards) for each parasitoid species. Distilled water was used in the untreated control. The treated egg cards were left to dry out for one hour. After that, each treated TLM egg card was exposed to 5 adult females of each tested parasitoid species for a period of 2 hours. Then these cards were placed in Petri dishes and kept in an incubator at $25^{\circ} \mathrm{C}$ till emergence. The rate of parasitized host eggs and emerging parasitoid adults were counted using the following equations;

$$
\begin{aligned}
& \text { Parasitism }(\%)=\frac{\text { No. of parasitized eggs (Black eggs) }}{\text { Total No. of exposed host eggs }} \times 100 \\
& \text { No. of parasitized eggs with } \\
& \text { Emergence }(\%)=\frac{\text { emergence hole }}{\text { Total No. of parasitized eggs }} \times 100
\end{aligned}
$$

\section{b. Exposing parasitoid females to host eggs prior to treatment:}

In this experiment, the above mentioned methodology, including experimental setup and number of replicates for each treatment were used. However, newly emerged parasitoid females were offered untreated TLM eggs for parasitization. After that, these parasitized host egg cards were treated with the tested bio-rational insecticides as indicated earlier.

\section{c. Exposing parasitoid females to treated filter paper in Petri dishes:}

The toxicity of the tested bio-rational insecticides were assessed against the trichogrammatid species by exposing the adult parasitoids to residues of a fresh dry pesticide film applied on filter papers inside glass Petri dishes. The recommended field rate of each bio-rational insecticide was directly sprayed on the filter papers ( 7 $\mathrm{cm}$ diameter) and left to dry out. The treated filter papers were placed inside the Petri dish $(7 \mathrm{~cm}$ diameter). Ten newly emerged females of each parasitoid species were released into Petri dish with treated filter paper and rapidly covered with fine plastic sheet. Small holes were made in the plastic covers to ease ventilation. One hour later, these females were collected and transferred to other clean Petri dish and kept in an incubator at $25^{\circ} \mathrm{C}, 70 \%$ R.H. Each treatment of bio-rational insecticide was replicated four times for each parasitoid species. Distilled water was used in the untreated control. The number of dead and survived parasitoids was counted $24 \mathrm{~h}$ post of treatment.

\section{Statistical analysis:}

Normality of data was tested by the Shapiro-Wilks test before further analysis. When a Shapiro-Wilk test indicated that data were normally distributed, data were analyzed by parametric analysis of variance (ANOVA) and then the Holm-Sidak or Student-Newman-Keuls methods were used for all pair wise multiple comparisons. When data were not normally distributed, a nonparametric Kruskal-Wallis ANOVA on ranks (H test) was used and Tukey's or Dunn's tests were used to compare treatment means at a 0.05 level of significance. Data were analyzed using SigmaPlot 12.3 (Systat Software Inc., 2011).

\section{RESULTS AND DISCUSSION}

\section{a. Exposing parasitoid adult females to treated TLM eggs: \\ Effects on parasitism percentage:}

As shown in Figure (1), all tested bio-rational insecticides have reduced percentages of parasitism irrespective of tested parasitoid species. Percentages of parasitism in control treatment reached $85,87.50,92.50$ and $75 \%$ in $T$. evanescens, $T$. cacoeciae, $T r$. bactrae and 
T. pretiosum, respectively. Data revealed that the tested insecticides significantly affected the number of parasitized TLM eggs. Spintor, proclaim and coragen severely affected the number of parasitized eggs that were treated before exposing to parasitoids. The lowest percentage of parasitism in treated TLM eggs exposed to $T$. pretiosum was recorded with coragen at $7.50 \%$. Spintor showed its highest toxic effect on the percentage of parasitism; being 10, 15 and $15 \%$ for T. pretiosum, $T$. evanescens and $T$. cacoeciae, respectively. The highest toxic effect of proclaim was observed in T. evanescens, T. pretiosum and T. cacoeciae at parasitism rate of $15 \%$ to all of them. Moreover, proclaim treatment has not caused significant differences between the four parasitoid species. Match had moderate toxic effect where the percentage of parasitism ranged between $3 \%$ for $T$. pretiosum to $62.50 \%$ for $T$. evanescence and $T$. cacoeciae. Dipel $2 \times$ had less toxic effect, where the rate of parasitism ranged between $52.50 \%$ for $T$. pretiosum and $82.50 \%$ for $T r$. bactrae (Figure 1). Statistical analyses indicated that percentages of parasitism by the four parasitoids differed significantly in dipel $2 \times\left(\mathrm{F}_{3,12}=\right.$ 4.88; $P=0.019)$, coragen $\left(\mathrm{F}_{3,12}=7.77 ; P=0.004\right)$ and match $\left(\mathrm{F}_{3,12}=6.40 ; P=0.008\right)$. However, no significant differences existed in control $\left(\mathrm{F}_{3,12}=2.26 ; P=0.134\right)$, spintor $\left(\mathrm{F}_{3,12}=2.79 ; P=0.086\right)$ and proclaim treatment $\left(\mathrm{F}_{3,12}=0.60 ; P=0.627\right)$.

Statistical analyses further proved that there were significant differences among rates of parasitism in TLM eggs treated with the tested bio-rational insecticides in $T$. evanescens $\left(\mathrm{F}_{5,12}=31.68 ; P=0.001\right)$, T. cacoeciae $\left(\mathrm{F}_{5,12}=22.32 ; P=0.001\right), \operatorname{Tr}$. bactrae $\left(\mathrm{F}_{5,12}=\right.$ $21.70 ; P=0.001)$ and $T$. pretiosum $\left(\mathrm{F}_{5,12}=33.87 ; P=\right.$ $0.001)$.

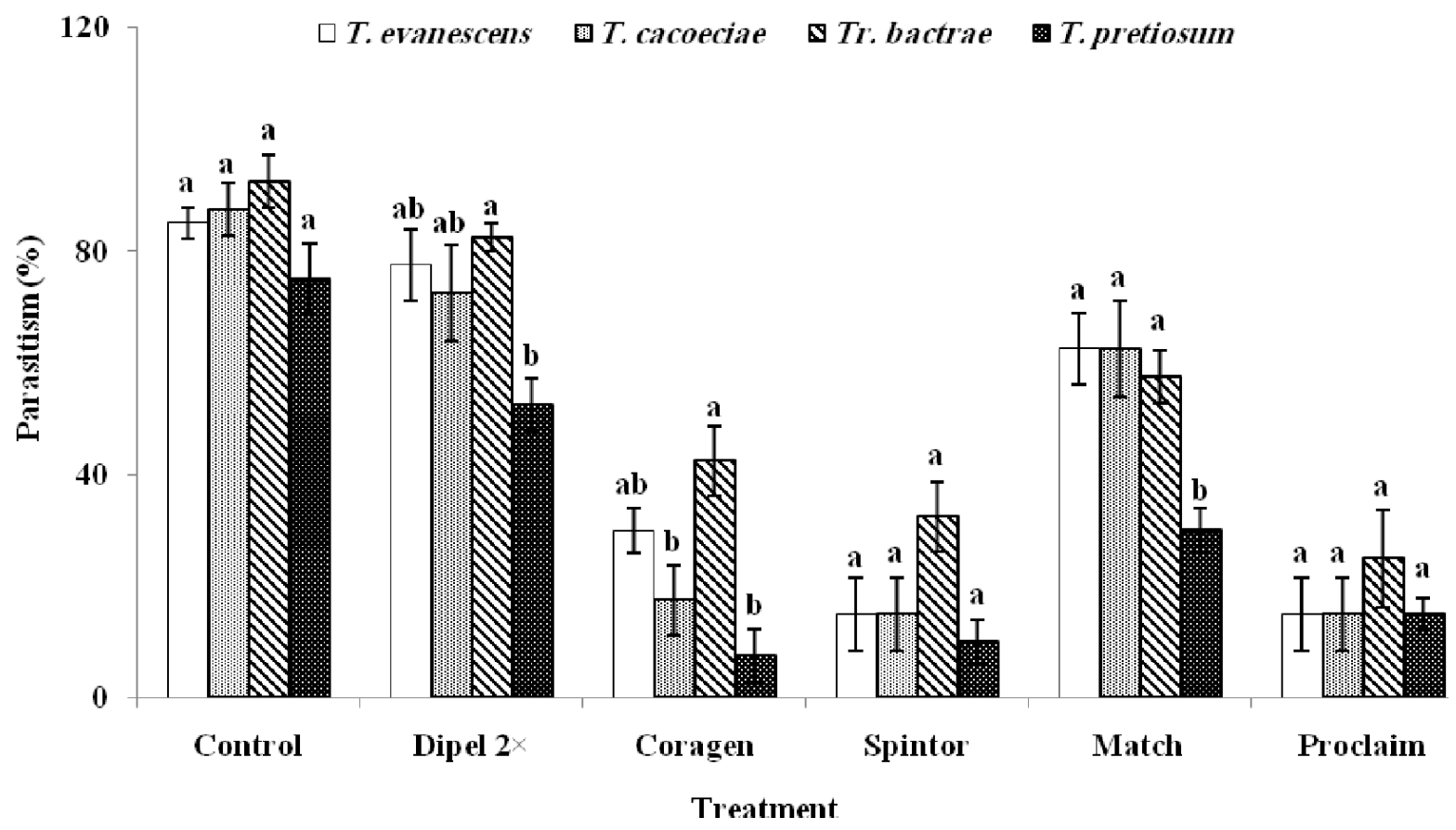

Figure (1): Mean percentages of parasitism $( \pm \mathrm{SE})$ by four trichogrammatid species in TLM eggs treated one hour pre-exposure to parasitoid with field rates of certain bio-rational insecticides. Bars with different letters in the same treatment indicate significant differences $(\mathrm{P}<0.05)$

\section{Effects on percentage of adult emergence:}

As shown in Figure (2), all tested bio-rational insecticides reduced adult emergence rates, irrespective of parasitoid species. Rates of emergence in control treatment reached $80,80,85$ and $65 \%$ in $T$. evanescens, $T$. cacoeciae, $T r$. bactrae and T. pretiosum, respectively. Based on the reduction in adult emergence rates, the toxicity of the tested bio-rational insecticides was in the order of spintor $>$ proclaim $>$ coragen $>$ match $>$ dipel $2 \times$. Clearly, Tr. bactrae was the least affected parasitoids with the tested insecticides at percentages of emergence of $75,25,22.50,42.50$ and $22.50 \%$ in dipel $2 \times$, coragen, spintor, match and proclaim treatments, respectively. On the other hand, T. pretiosum was the most affected parasitoid with pesticide treatment at percentages of adult emergence of $37.50,2.50,2.50$,
22.50 and $5 \%$ in the respective bio-rational insecticide treatments (Figure 2).

Statistical analysis showed significant differences in rates of adult emergence between the studied biorational insecticides, i.e., dipel $2 \times\left(\mathrm{F}_{3,12}=9.72 ; P=\right.$ $0.002)$, coragen $\left(\mathrm{F}_{3,12}=3.57 ; P=0.047\right)$ and spintor $\left(\mathrm{F}_{3,12}=4.47 ; P=0.025\right)$. However, no significant differences were observed in control $\left(\mathrm{F}_{3,12}=3.60 ; P=\right.$ 0.046), match $\left(\mathrm{F}_{3,12}=2.95 ; P=0.076\right)$ and proclaim treatment $\left(\mathrm{F}_{3,12}=2.22 ; P=0.138\right)$.

Statistical analyses also revealed that significant differences existed in percentages of adult emergence in T. evanescens $\left(\mathrm{F}_{5,12}=29.42 ; P=0.001\right), T$. cacoeciae $\left(\mathrm{F}_{5,12}=35.40 ; P=0.001\right)$, Tr. bactrae $\left(\mathrm{F}_{5,12}=29.31 ; P=\right.$ $0.001)$ and $T$. pretiosum $\left(\mathrm{F}_{5,12}=30.12 ; P=0.001\right)$. 


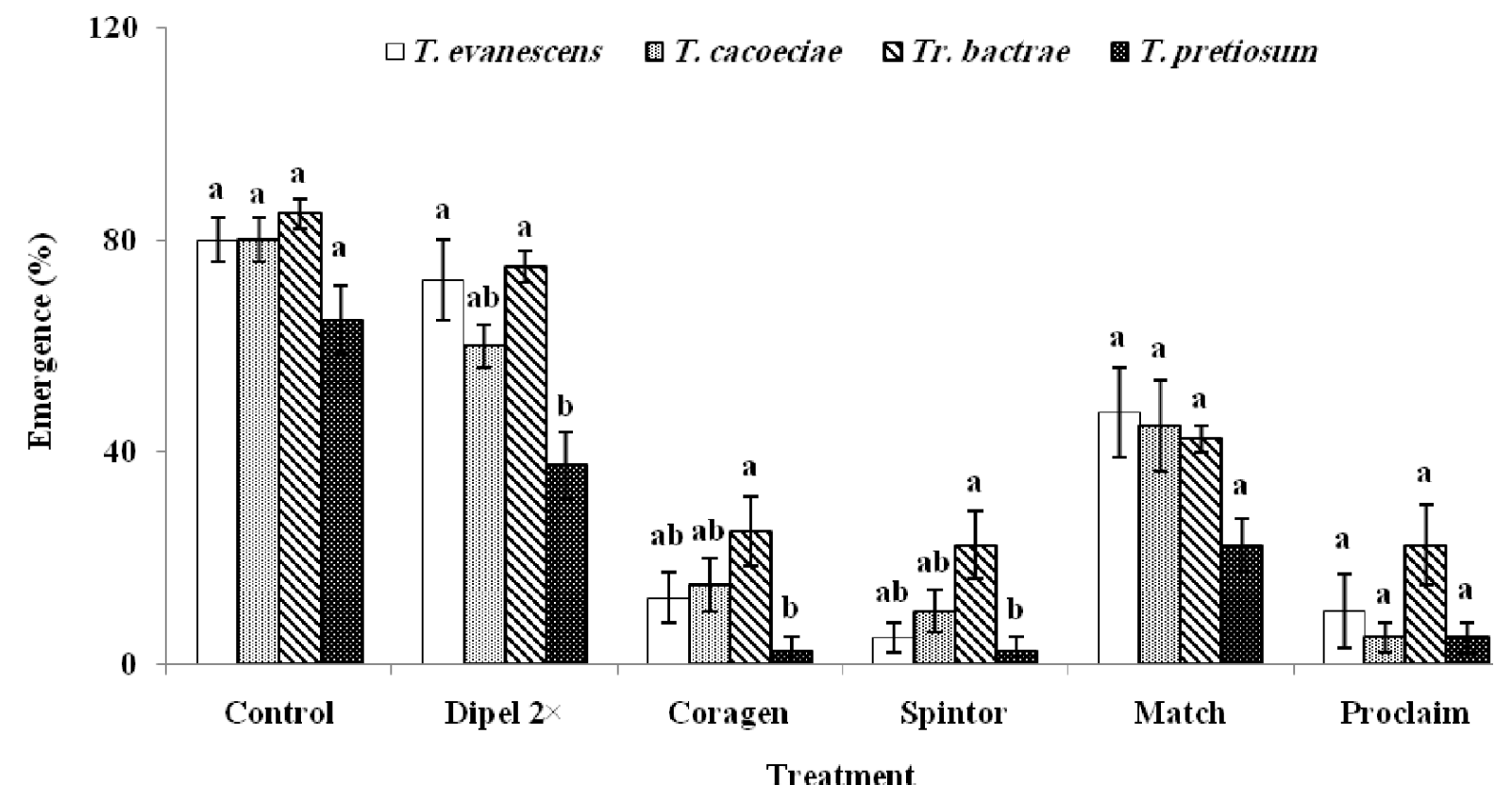

Figure (2): Mean percentages of adult emergence $( \pm \mathrm{SE})$ of four trichogrammatid species in TLM eggs treated one hour pre-exposure to parasitoids with field rates of certain bio-rational insecticides. Bars with different letters in the same treatment indicate significant differences $(\mathrm{P}<0.05)$

\section{b. Exposure of parasitoid females to TLM eggs prior to treatment: \\ Effects on percentage of parasitism:}

As shown in Figure (3), all tested bio-rational insecticides reduced rates of parasitism irrespective of parasitoid species. Rates of parasitism in control treatment reached $92.50,95,97.50$ and $82.50 \%$ in $T$. evanescens, T. cacoeciae, Tr. bactrae and T. pretiosum, respectively. The lowest percentages of parasitism in treated host eggs after being exposed to $T$. pretiosum were recorded with spintor and coragen at 10 and $25.50 \%$, respectively. Proclaim caused high toxicity for all tested parasitoid species with no significant differences, where the parasitism percentage ranged between $27.50 \%$ in $T$. pretiosum and $37.50 \%$ in $T$. evanescens. Match was less toxic and the percentage of parasitism ranged between $57.50 \%$ for $T$. pretiosum to $82.5 \%$ for $T$. evanescens. Dipel $2 \times$ didn't display noticeable effects, where the percentages of parasitism ranged between $70 \%$ for $T$. pretiosum and $85 \%$ for $T$. evanescens (Figure 3).

Treatment of TLM parasitized eggs by bio-rational insecticides caused significant differences in terms of successful rates of parasitism among tested parasitoids in coragen $\left(\mathrm{F}_{3,12}=7.71 ; P=0.004\right)$, spintor $\left(\mathrm{F}_{3,12}=13.68\right.$; $P=0.001)$ and match $\left(\mathrm{F}_{3,12}=3.56 ; P=0.047\right)$. However, no significant differences were observed in case of control $\left(\mathrm{F}_{3,12}=2.86 ; P=0.081\right)$, dipel $2 \times\left(\mathrm{F}_{3,12}=1.54 ; P=\right.$ $0.254)$ and proclaim treatment $\left(\mathrm{F}_{3,12}=0.58 ; P=0.640\right)$.

Similarly, statistical analyses also showed that the rates of parasitism in TLM treated with certain biorational insecticides differed significantly in $T$. evanescens $\left(\mathrm{F}_{5,12}=21.58 ; P=0.001\right), T$. cacoeciae $\left(\mathrm{F}_{5,12}=16.71 ; P=0.001\right)$, Tr. bactrae $\left(\mathrm{H}_{5}=19.87 ; P=\right.$ $0.001)$ and $T$. pretiosum $\left(\mathrm{F}_{5,12}=26.45 ; P=0.001\right)$.

\section{Effects on percentages of adult emergence:}

As shown in Figure (4), all tested bio-rational insecticides reduced percentages of adult emergence irrespective of parasitoid species. Rates of parasitoid emergence in control treatment reached 87.50, 90, 95 and $75.50 \%$ in $T$. evanescens, T. cacoeciae, Tr. bactrae and $T$. pretiosum, respectively. Data revealed that exposing parasitoid females to TLM treated eggs with spintor resulted in the lowest percentages of emergence for all tested parasitoids at 17.50, 35, 30 and 5\% in $T$. evanescens, T. cacoeciae, Tr. bactrae and T. pretiosum, respectively. Proclaim came second after spintor in its toxic effect at percentages of parasitoid emergence of $10,15,25$ and $10 \%$ for the respective parasitoids (Figure 4).

The respective percentages of adult emergence for coragen were $32.50,32.50,55$ and $7.50 \%$, and those for match was $72.50,52.50,60$ and 42.50. Moreover, dipel $2 \times$ treatment showed the highest percentages of emergence at $77.50,70,72.50$ and $57.50 \%$ for $T$. evanescens, T. cacoeciae, Tr. bactrae and T. pretiosum, respectively.

Statistical analyses showed significant differences in rates of adult emergence in TLM-treated-eggs for $T$. evanescens $\left(\mathrm{F}_{5,12}=37.28 ; P=0.001\right), T$. cacoeciae $\left(\mathrm{F}_{5,12}=27.75 ; P=0.001\right)$, Tr. bactrae $\left(\mathrm{F}_{5,12}=16.68 ; P=\right.$ $0.001)$ and $T$. pretiosum $\left(\mathrm{F}_{5,12}=30.33 ; P=0.001\right)$.

Based on the tested bio-rational insecticides, statistical analyses proved a significant differences between coragen $\left(\mathrm{F}_{3,12}=13.64 ; P=0.001\right)$, spintor $\left(\mathrm{F}_{3,12}=5.18 ; P=0.016\right)$ and match $\left(\mathrm{F}_{3,12}=4.21 ; P=\right.$ $0.030)$. On the other hand, no significant difference existed in terms of rates of emergence in control $\left(\mathrm{F}_{3,12}=\right.$ 3.10; $P=0.067)$, proclaim $\left(\mathrm{F}_{3,12}=1.33 ; P=0.310\right)$ and dipel $2 \times\left(\mathrm{F}_{3,12}=3.39 ; P=0.054\right)$. 


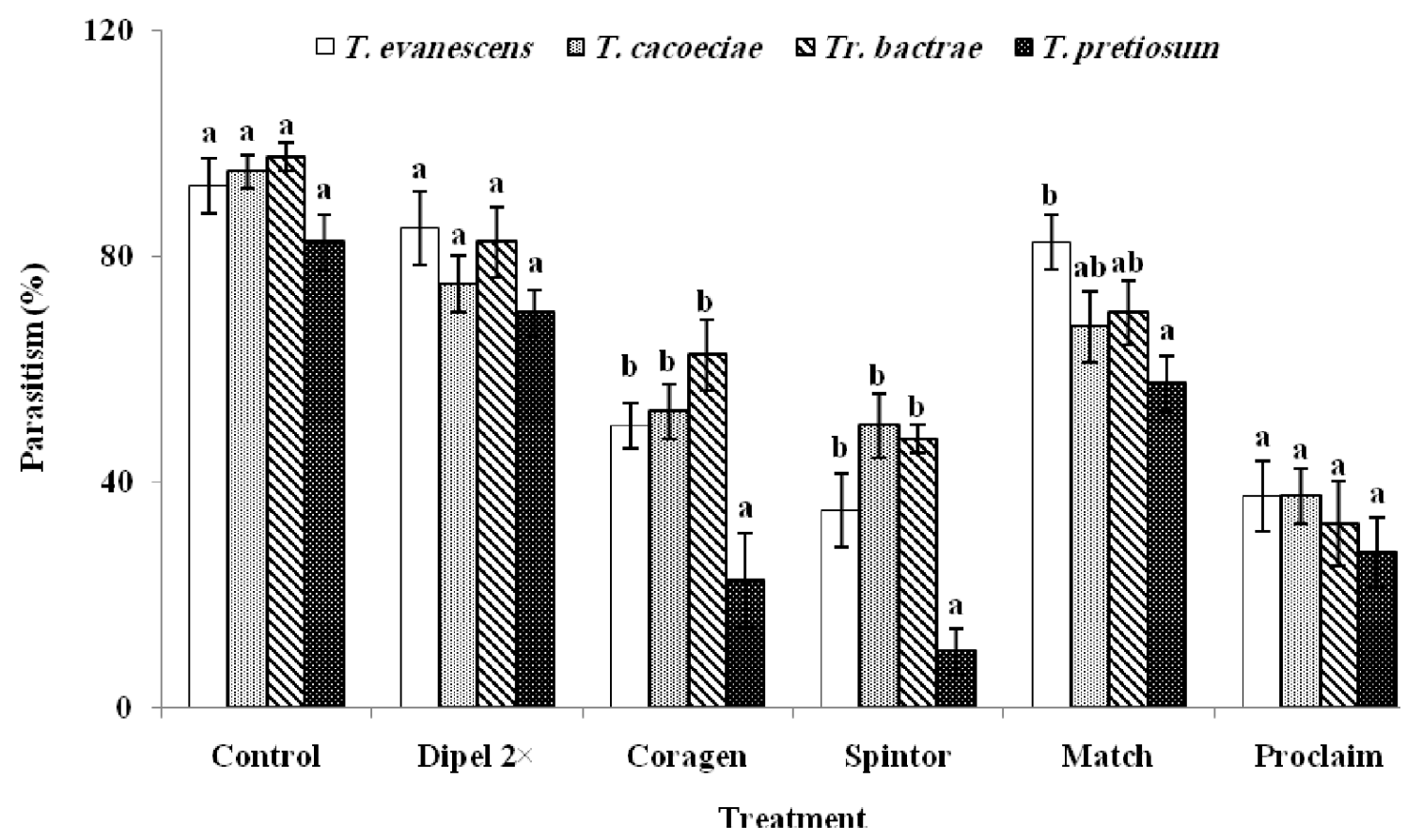

Figure (3): Mean percentages of parasitism ( \pm SE) by four trichogrammatid species in TLM eggs treated one hour post-exposure to parasitoids with field rates of certain bio-rational insecticides. Bars with different letters in the same treatment indicate significant differences $(\mathrm{P}<0.05)$

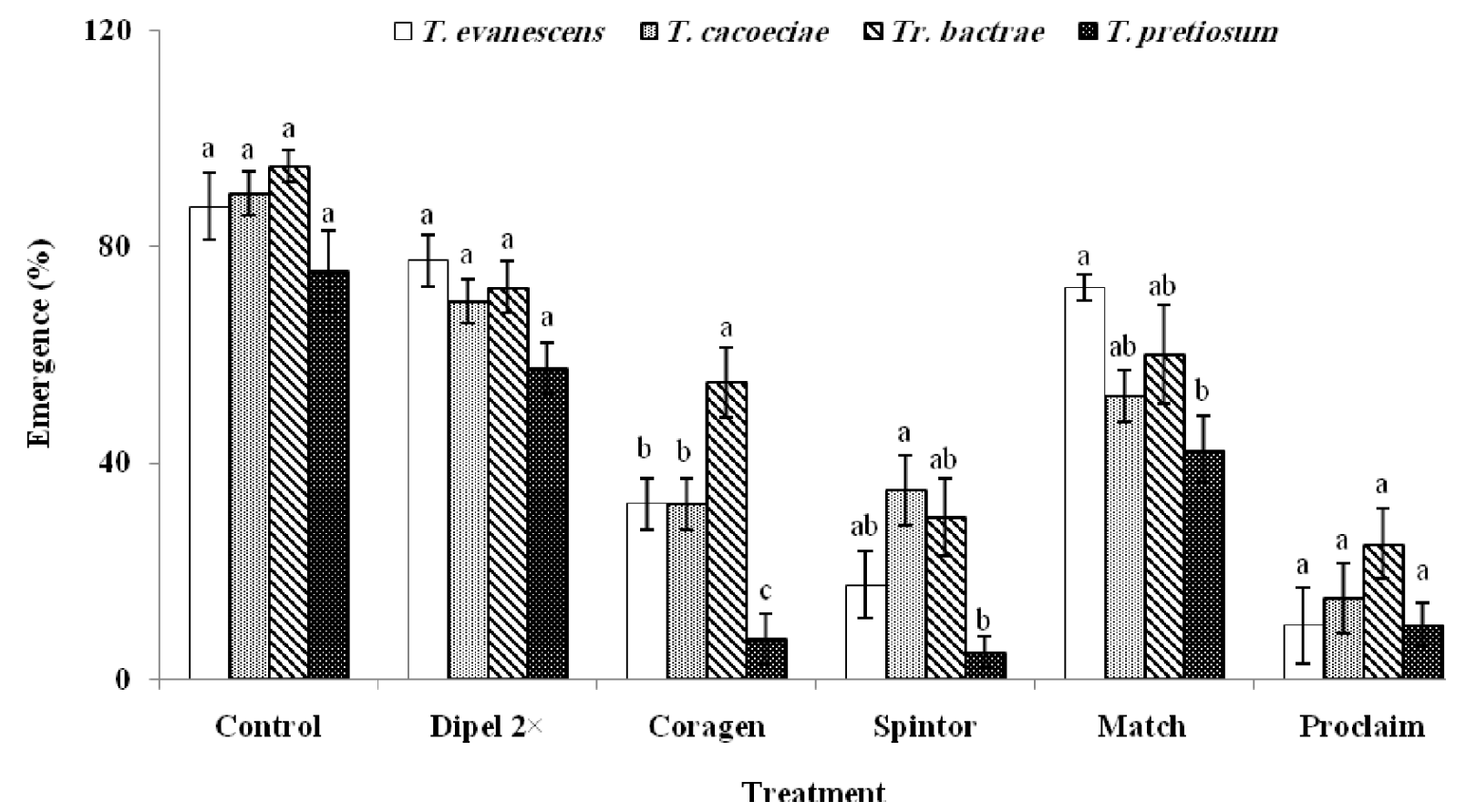

Figure (4): Mean Percentages of adult emergence $( \pm \mathrm{SE})$ of four trichogrammatid species in TLM eggs treated one hour post-exposure to parasitoids with field rates of certain bio-rational insecticides. Bars with different letters in the same treatment indicate significant differences $(\mathrm{P}<0.05)$ 
c. Exposure of parasitoid adult females to insecticide residues:

The obtained data revealed that the mortality percentages of parasitoid females exposed to different bio-rational insecticide residues on a filter paper differed significantly among tested parasitoids (Figure 5). Exposing adults of parasitoids to residues of coragen caused the highest percentages of mortality at 70,67.50, 60 and $90 \%$ for T. evanescens, T. cacoeciae, Tr. bactrae and $T$. pretiosum, respectively. Spintor came second in its effect on adult mortality at mortality percentages of $62.50,62.50,55$ and $85 \%$ for the respective parasitoids. Proclaim also caused higher percentages of mortality at $27.50,77.50,65$ and $92.50 \%$ for the respective parasitoids. Match was moderately toxic to the parasitoids at respective mortality percentages of 17.50 , 25,35 and $37.50 \%$. Meanwhile, dipel $2 \times$ proved to be slightly toxic at respective mortality percentages of 10 , 7.50, 10 and $12.50 \%$ (Figure 5).
Statistical analysis showed high significant differences of the parasitoid mortality rates between the tested bio-rational insecticides. There were significant differences in mortality percentages in proclaim treatment $\left(\mathrm{F}_{3,12}=24.31 ; P=0.001\right)$. However, no significant difference was found among rates of mortality in all tested parasitoids in control $\left(\mathrm{H}_{3}=2.22\right.$; $P=0.528)$, dipel $2 \times\left(\mathrm{F}_{3,12}=0.21 ; P=0.887\right)$, coragen $\left(\mathrm{F}_{3,12}=3.46 ; P=0.051\right)$, match $\left(\mathrm{F}_{3,12}=2.34 ; P=0.125\right)$ and spintor treatment $\left(\mathrm{F}_{3,12}=1.57 ; P=0.247\right)$.

Moreover, statistical analyses revealed that significant differences mortality percentages when parasitoid adults exposed to bio-rational insecticides residues in $T$. evanescens $\left(\mathrm{F}_{5,12}=21.77 ; P=0.001\right), T$. cacoeciae $\left(\mathrm{H}_{5}=19.75 ; P=0.001\right)$, Tr. bactrae $\left(\mathrm{F}_{5,12}=\right.$ $18.45 ; P=0.001)$ and $T$. pretiosum treatment $\left(\mathrm{F}_{5,12}=\right.$ 41.464; $P=0.001)$.

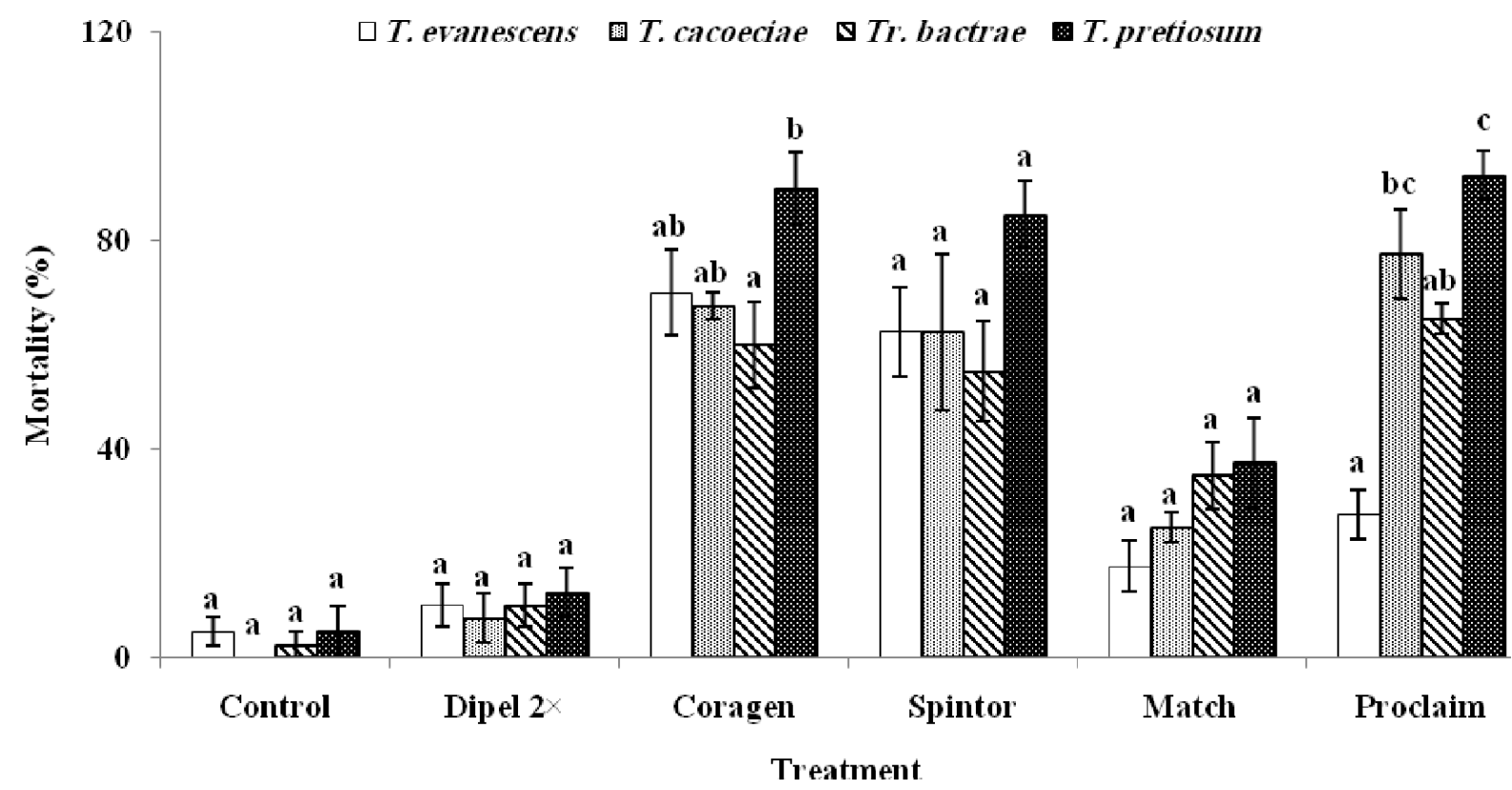

Figure (5): Mean $( \pm$ SE) of adult mortality of four trichogrammatid parasitoids exposed to residues of certain biorational insecticides, on a filter paper. Bars with different letters in the same treatment indicate significant differences $(\mathrm{P}<0.05)$

\section{DISCUSSION}

Despite the success of biological control in pest control, chemical insecticides are still an important control tool, indispensable for the control of TLM in tomato fields. The integration of chemical and biological control is often critical to the success of an integrated pest management program (El-Wakeil et al., 2013). However, modern integrated plant protection strategy has recommended, optimal use of selective insecticides that are less harmful to natural enemies (Tillman and Mulrooney, 2000; Stark et al., 2007), which requires more about their adverse effects on the behavioural and biological attributes of these organisms (Tillman and Mulrooney, 2000; Stark et al., 2007). Biorational insecticides are a distinct group, having selective toxicity and different modes of action as compared to commonly used conventional insecticides. However, no pesticide is $100 \%$ safe and non-toxic toward non target organisms, particularly parasitoids (Desneux et al., 2007; Stark and Banks, 2003). Fortunately, in Egypt, several new products of the biorational pesticides are available and commercially used against TLM. Among the most novel bio-rational insecticides with selective properties are emamectin benzoate $\left(\right.$ proclaim $\left.^{\mathbb{B}}\right)$, chlorantraniliprole $\left(\right.$ coragen $\left.^{\circledR}\right)$ and spinosad (spintor $\left.{ }^{\circledR}\right)$. Lufenuron $\left(\right.$ match $\left.^{\circledR}\right)$ is an acylurea insect growth regulator belonging to the group of benzoyl-phenyl-ureas (BPUs) and is classified as an insect development inhibitor (IDI) (Whiting et al., 2000). Dipel ${ }^{\circledR}$ is a biological insecticide containing the naturally occurring microorganism Bacillus thuringiensis v. kurstaki (Btk) (Lambert and Peferoen, 1992). 
In this study, results of the assessment of the selected bio-rational insecticides showed various degree of susceptibility of the four trichogrammatid species to the tested insecticides commonly used in tomato fields against TLM. Spinosad (spintor) came first in terms of reducing parasitism and adult emergence followed by emamectin benzoate (proclaim), chlorantraniliprole (coragen ${ }^{\circledR}$ ), lufenuron (match), and B. thuringiensis (dipel $2 \times^{\circledR}$ ) either when TLM eggs treated before or after exposure to the parasitoid. The high toxicity of spinosad to the four tested trichogrammatid species in the current study is in agreement with those reported earlier for other species of Trichogramma e.g. T. galloi (Consoli et al., 2001), T. exiguum (Suh et al.. 2000), T. pretiosum (Bueno et al., 2008) and T. platneri (Jay et al., 2001). Emamectin benzoate (proclaim ${ }^{\circledR}$ ) showed high toxicity to the tested parasitoids. These results are also in line with those reported for $T$. chiolnis (Sattar et al., 2011; Dilbar et al., 2012). However, Hew-Kapuge et al. (2003) reported moderate toxic effect of emamectin benzoate to $T$. brassicae with mortality rate of $23-64 \%$. Regarding the toxicity of chlorantraniliprole, the present findings agreed with the work of Preetha et al. (2010) and Dilbar et al. (2012) who reported that chlorantraniliprole had less knockdown effect to $T$. chilonis as compared to other insecticides. Concerning the slightly harmful effect of lufenuron, the present findings agree with those of Vianna et al. (2009) who found that lufenuron had lowest negative impacts on parasitism and populations of T. pretiosum. Also, Sattar et al. (2011) recorded that lufenuron had low negative effects on $T$. chilonis adult survival, but it significantly decreased parasitization capacity. Lufenuron caused $61.80 \%$ reduction in the parasitism capacity of $T$. pretiosum under laboratory conditions (Carvalho et al., 2005). As for B. thuringiensis, the obtained results are consistent to those of Vianna et al. (2009) who concluded that $B$. thuringiensis had the lowest negative effects on parasitism of T. pretiosum. Shoeb (2005) also found that protecto ( $B$. thuringiensis) had the least deleterious effect on $T$. evanescens.

The obtained data also confirmed high susceptibility of the tested parasitoid wasps to spintor, proclaim and coragen and demonstrated that dipel $2 \times$ is more compatible and/or suitable to conserve natural or released populations of Trichogramma wasps. Nevertheless, as in the case of using other insecticides, it is useful to bear in mind that under field conditions, eggs would receive a much lower dose, and many eggs such as those deposited on the underside of leaves might not even be exposed to the insecticides (Suh et al., 2000).

\section{CONCLUSION}

The conclusion drawn from the above results indicated that all tested bio-rational insecticides caused various toxicity effects against the four Trichogrammatid egg parasitoid species. They have already induced significant inhibition in parasitism efficiency, adult emergence, beside their toxicity to adult parasitoids, indicating that parasitoid species had varying degree of susceptibility. The tested insecticides were either harmful (spintor, coragen and proclaim) or moderately harmful (match) or slightly harmful (dipel $2 \mathrm{x}$ ). Despite the effectiveness of theses insecticides in controlling TLM under field conditions (Abd El-Hady et al., 2013), unfortunately, they would also cause significant reduction in the population of the coexistence parasitoids. In this respect, the obtained results support the idea that the use of different biotactics such as bio-rational insecticides in conjunction with the release of egg parasitoids could offer great opportunity to control of TLM, with timely manner and avoiding the time of insecticide application for a sufficient period as much as possible.

\section{ACKNOWLEDGEMENT}

The authors would like to thank Prof. Dr. Ahmed H. El-Heneidy (Agricultural Research Center) for providing Trichogrammatoidea bactrae, Prof. Dr. Essam A. Agamy (Cairo University) for providing Trichogramma cacoeciae, Prof. Dr. Leopaldo Caltigrone (University of California) and Eng. Usama M. El-Kady for providing the specimens of Trichogramma pretiosum, and Dr. Islam S. Shehata (Suez Canal University) for his support in performing the statistical analysis.

\section{REFERENCES}

Abd El-Hady, M. A., M. A. M. Osman and A. A. Sarhan 2013. Evaluation the efficacy of certain bio-rational insecticides on Tuta absoluta (Lepidoptera, Gelechiidae) on tomatoes under laboratory and field conditions. JAPP, Suez Canal Univ., 1:1-6.

Bueno, A. F., R. C. O. F. Bueno, J. R. P. Parra and S. Vieiras 2008. Effects of pesticides used in soybean crops to the egg parasitoid Trichogramma pretiosum. Ciênc. Rural, 38:1495-1503.

Caltagirone, L. E. and C. B. Huffaker 1980. Benefits and risks of using predators and parasites for controlling pests. Bull. Ecol. Soc. Am., 31: 103109.

Carvalho, G. A., D. T. Rezende, A. P. Moura, V. F. Moscardini, O. Lasmar and J. R. Souza 2005. Selectivity of flubendiamide, a new insecticide used to control tomato pests in Brazil to Trichogramma pretiosum Riley (Hymenoptera: Trichogrammatidae). Egg Parasitoid News, IOBC, 17: $60 \mathrm{pp}$.

Consoli, F. L., P. S. M. Botelho and J. R. P. Parra 2001. Selectivity of insecticides to the egg parasitoid Trichogramma galloi Zucchi (Hymenoptera: Trichogrammatidae). J. Appl. Entomol., 125: 37 43.

Desneux, N., A. Decourtye and J. M. Delpuech 2007. The sublethal effects of pesticides on beneficial arthropods. Annu. Rev. Entomol., 52:81-106.

Desneux N., E. Wajnberg, K. A. G. Wyckhuys, G. Burgio, S. Arpaia, C. A. Narvaez-Vasquez, J. Gonzalez-Cabrera, D. Catalan Ruescas, E. Tabone, J. Frandon, J. Pizzol, C. Poncet, T. Cabello and A. Urbaneja 2010. Biological invasion of European tomato crops by Tuta 
absoluta: ecology, geographic expansion and prospects for biological control. J. Pest Sci., 83: 197-215.

Desneux N., M. G. Luna, T. Guillemaud and A. Urbaneja 2011. The invasive South American tomato pinworm, Tuta absoluta, continues to spread in Afro-Eurasia and beyond: the new threat to tomato world production. J. Pest Sci., 84: 403-408.

Dilbar, H., A. Amjad, M. H. Muhammad Mushtaq, A. Saira, M. Saleem and N. Sajid 2012. Evaluation of toxicity of some new insecticides against egg parasitoid Trichogramma chilonis (Ishii) (Hymenoptera: Trichogrammitidae). Pak. J. Zool., 44(4): 1123-1127.

El-Wakeil, N., N. Gaafar, A. Sallam and C. Volkmar 2013. Side effects of insecticides on natural enemies and possibility of their integration in plant protection strategies. In: Insecticides development of safer and more effective technologies. Stanislav Trdan (Ed.), pp 1-56. InTech, $\quad$ http://cdn.intechopen.com/pdfswm/42191.pdf

EPPO, 2005. EPPO datasheets on quarantine pests: Tuta absoluta. EPPO Bull. 35: 434-435.

Hafez, M. B., A. Schmitt and A. Hassan 1999. The side effects of plant extracts and metabolites of Reynoutria sachalinensis (F. Schmidt) Nakai and conventional fungicides on the beneficial organism Trichogramma cacoeciae Marchal (Hymenoptera: Trichogrammatidae). J. Appl. Entomol., 123: 363-368.

Hewa-kapuge, S., S. Mcdougall and A. A. Hoffmann 2003. Effect of methoxyfenozide, indoxacarb, and other insecticides on the beneficial egg parasitoid Trichogramma brassicae (Hymenoptera: Trichogrammatidae) under laboratory and field conditions. J. Entomol. Sci., 96: 1083-1090.

Jay, F. B., E. D. John, D.D. Michael and H. B. ElIzabeth 2001. Effect of pesticides on Colpoclypeus florus (Hymenoptera: Eulophidae) and Trichogramma platneri (Hymenoptera: Trichogrammatidae), parasitoids of leafrollers in Washington. J. Econ. Entomol., 94(5): 10751084.

Lambert, B and M. Peferoen 1992. Insecticidal promise of Bacillus thuringiensis. Facts and mysteries about a successful biopesticide. BioScience, 42: $112-122$

Picanco, M. C., L. Bacci, A. L. B. Crespo, M. M. Miranda and J.C. Martins 2007. Effect of integrated pest management practices on tomato production and conservation of natural enemies. Agric. For. Entomol., 9: 327-335.

Pratissoli, D. and J. R. P. Parra 2001. Selection of strains of Trichogramma pretiosum Riley (Hymenoptera: Trichogrammatidae) to control the tomato leafminer moths Tuta absoluta (Meyrick) and Phthorimaea operculella (Zeller) (Lepidoptera: Gelechiidae). Neotrop. Entomol., 30(2): 277-282.
Preetha, G., T. Manoharan, J. Stanley and S. Kuttalam 2010. Impact of chlornicotinyl insecticide, imidacloprid on egg, egg-larval and larval parasitoids under laboratory conditions. JPPR, 50: 535-540.

Sattar, S. F., A. R. Saljoqi, M. Arif, H. Sattar and J. Qazi 2011. Toxicity of some new insecticides against Trichogramma chilonis (Hymenoptera: Trichogrammatidae) under laboratory and extended laboratory conditions. Pak. J. Zool., 43(6): 1117-1125.

Shoeb, M. A. 2005. Comparativeness of chemical, natural and bacterial insecticides on some biological aspects of the egg parasitoid Trichogramma evanescens (West.). J. Agric. Sci., Mansoura Univ., 30(8): 4821-4826.

Stark, J. D. and J. E. Banks 2003. Population-level effects of pesticides and other toxicants on arthropods. Annu. Rev. Entomology, 48: 505519.

Stark, J. D., R. I. Vargas and J. E. Banks 2007. Incorporating ecologically relevant measures of pesticide effect for estimating the compatibility of pesticides and biocontrol agents. J. Econ. Entomol., 100: 1027-1032.

Suh, C. P. C., D. B. Orr and W. Van Duynj 2000. Effect of insecticides on Trichogramma exiguum (Trichogrammatidae: Hymenoptera) preimaginal development and adult survival. J. Econ. Entomol., 93: 577-583.

Systat Software Inc., 2011. In SigmaPlot for Windows version 12; Systat Software Inc.: Chicago, IL, USA.

Temerak, S. A. 2011. The status of Tuta absoluta in Egypt from 2009-2011. Joint, International symposium on management of Tuta absoluta (tomato borer) Conf., EPPO/IOPC/FAO/NEPP, Agadir, Morocco, $18 \mathrm{pp}$.

Tillman, P. G. and J.E. Mulrooney 2000. Effect of selected insecticides on the natural enemies Colleomegilla maculata and Hippodamia convergens (Coccinellidae), Geocoris punctipes (Lygaeidae), and Bracon mellitor, Cardiochiles nigriceps, and Cotesia marginiventris (Braconidae) in cotton. J. Econ. Entomol., 93: 1638-1643.

Tropea Garzia, G., G. Siscaro, A. Biondi and L. Zappalà 2012. Tuta absoluta, a South American pest of tomato now in the EPPO region: Biology, distribution and damage. EPPO Bull., 42: 205210.

Vianna, U. R., D. Pratissoli, J. C. Zanunico, E. R. Lima, J. Brunner, F. F. Pereira and J. E. Serrao 2009. Insecticide toxicity to Trichogramma pretiosum (Hymenoptera: Trichogrammatidae) females and effect on descendant generation. Ecotoxicology, 18: $180-186$.

Whiting, D. C., L. E. Jamieson and P. G. Connolly 2000. Pre - and post-harvest effects of lufenuron on Epiphyas postvittana (Lepidoptera: Tortricidae). J. Econ. Entomol., 93(3): 673-679. 